\title{
Hydrogen sulfide maintains dental pulp stem cell function via TRPV1-mediated calcium influx
}

Ruili Yang ${ }^{1,2,3}$, Yi Liu ${ }^{4}$, Tingting Yu ${ }^{1,2,3}$, Dawei Liu ${ }^{1,2,3}$, Songtao Shi ${ }^{3}$, Yongsheng Zhou ${ }^{2,5}$ and Yanheng Zhou ${ }^{1,2}$

\begin{abstract}
Hydrogen sulfide $\left(\mathrm{H}_{2} \mathrm{~S}\right)$, an endogenous gasotransmitter, mediated a variety of biological processes through multiple signaling pathways, and aberrant $\mathrm{H}_{2} \mathrm{~S}$ metabolism has been associated with mesenchymal stem cell (MSC) dysfunction. Here we employed the small interfering RNA treatment for cystathionine $\beta$-synthase (CBS), cystathionine $\gamma$-lyase, the main enzymes to synthesize $\mathrm{H}_{2} \mathrm{~S}$, and CBS-knockout mice to analyze the effect of $\mathrm{H}_{2} \mathrm{~S}$ on dental pulp homeostasis. We showed that $\mathrm{H}_{2} \mathrm{~S}$ deficiency attenuated dental pulp stem cell (DPSC) osteogenic/dentinogenic differentiation in vitro and in vivo with enhanced cell proliferation. Mechanically, $\mathrm{H}_{2} \mathrm{~S}$ facilitated the transient receptor potential action channel subfamily $\vee$ member 1 -mediated calcium $\left(\mathrm{Ca}^{2+)}\right.$ influx, which subsequently activated the $\beta$ catenin pathway. While $\mathrm{H}_{2} \mathrm{~S}$ deficiency decreased $\mathrm{Ca}^{2+}$, resulting in glycogen synthase kinase-3 $\beta$-mediated $\beta$-catenin degradation, which controls proliferation and differentiation of DPSCs. Consistently, $\mathrm{H}_{2} \mathrm{~S}$-deficient mice displayed disturbed pattern of dental pulp and less dentin formation. In this study, we identified a previously unknown mechanism by which $\mathrm{H}_{2} \mathrm{~S}$ regulates DPSC lineage determination and dental pulp homeostasis.
\end{abstract}

\section{Introduction}

Hydrogen sulfide $\left(\mathrm{H}_{2} \mathrm{~S}\right)$ could freely diffuse through cell membranes to elicit various cellular events. $\mathrm{H}_{2} \mathrm{~S}$ is synthesized by three enzymes, namely cystathionine $\beta$ synthase (CBS), cystathionine $\gamma$-lyase (CSE), and $3-$ mercaptopyruvate sulfurtransferase (MPST) from Lcysteine $^{1}$. Alternations of $\mathrm{H}_{2} \mathrm{~S}$ metabolism have been linked to osteoporosis and $\mathrm{T}$ cell-related immune disorders $^{2,3}$. Endogenous $\mathrm{H}_{2} \mathrm{~S}$ is essential to maintain differentiation and proliferation of neural stem cells and human-induced pluripotent stem cells, and to restore the function of endothelial progenitor cell and mesenchymal

\footnotetext{
Correspondence: Yongsheng Zhou (kqzhouysh@hsc.pku.edu.cn) or Yanheng Zhou (yanhengzhou@vip.163.com)

'Department of Orthodontics, Peking University School and Hospital of Stomatology, 100081 Beijing, China

${ }^{2}$ National Engineering Laboratory for Digital and Material Technology of Stomatology, Beijing Key Laboratory of Digital Stomatology, 100081 Beijing, China

Full list of author information is available at the end of the article Edited by A.E. Sayan
}

stem cells (MSCs) to ensure bone homeostasis ${ }^{4,5}$. Our previous studies showed that $\mathrm{H}_{2} \mathrm{~S}$ deficiency resulted in bone marrow MSC impairment caused by $\mathrm{H}_{2} \mathrm{~S}$ deficiency reduced sulfhydration of combined $\mathrm{Ca}^{2+}$ transient receptor potential (TRP)-mediated (transient receptor potential action channel subfamily $\mathrm{V}$ member 3 (TRPV3), TRPV6, and TRPM4) aberrant $\mathrm{Ca}^{2+}$ influx ${ }^{6} . \mathrm{H}_{2} \mathrm{~S}$ donor was also reported to prevent trabecular bone loss induced by ovariectomy via increased Wnt ligands Wnt16, Wnt2b, Wnt6, and Wnt10b in the bone marrow ${ }^{7}$.

The oral cavity is abundant with a plethora of bacteria, some of which are well known to produce $\mathrm{H}_{2} \mathrm{~S}$. When the dynamic ecological equilibrium in the biofilm is disturbed, bacteria may elicit oral diseases such as caries, gingivitis, and periodontitis ${ }^{8}$. Several studies have indicated the role of $\mathrm{H}_{2} \mathrm{~S}$ in dental stem cells ${ }^{9}$. Dental pulp stem cells (DPSCs), isolated from dental pulp, were reported to be highly proliferative and capable of differentiating into a variety of cells including odontoblasts, osteoblasts, adipocytes, and neural cells.

\section{(c) 2018 The Author(s)}

(c) (i) Open Access This article is licensed under a Creative Commons Attribution 4.0 International License, which permits use, sharing, adaptation, distribution and reproduction c. in any medium or format, as long as you give appropriate credit to the original author(s) and the source, provide a link to the Creative Commons license, and indicate if changes were made. The images or other third party material in this article are included in the article's Creative Commons license, unless indicated otherwise in a credit line to the material. If material is not included in the article's Creative Commons license and your intended use is not permitted by statutory regulation or exceeds the permitted use, you will need to obtain permission directly from the copyright holder. To view a copy of this license, visit http://creativecommons.org/licenses/by/4.0/. 


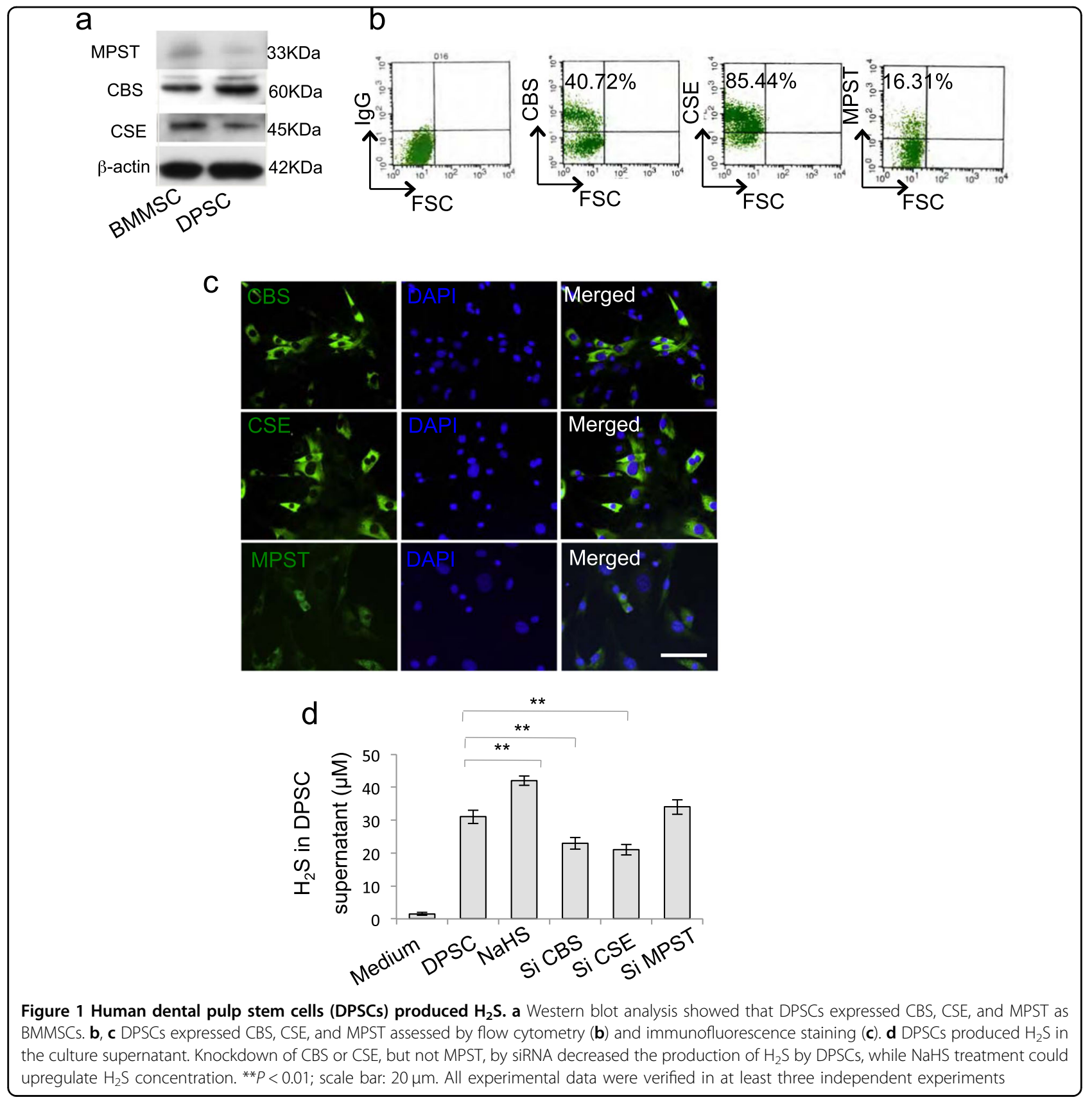

DPSCs could be induced to generate bone and dentin and play an important role in maintaining dental pulp and dentin homeostasis ${ }^{10}$. Recently, studies showed that $\mathrm{H}_{2} \mathrm{~S}$ increased DPSC hepatic differentiation ${ }^{11,12}$. Exogenous $\mathrm{H}_{2} \mathrm{~S}$ induced DPSC apoptosis by activating mitochondrial pathway apoptosis ${ }^{13} \cdot \mathrm{H}_{2} \mathrm{~S}$ may also be involved in periodontal ligament stem cell proliferation and differentiation and orthodontic tooth movement ${ }^{14-17}$. However, it remains unclear as to how $\mathrm{H}_{2} \mathrm{~S}$ molecularly maintains homeostasis of DPSCs and dental pulp.
In this study, we showed that the gasotransmitter $\mathrm{H}_{2} \mathrm{~S}$ is essential to maintain DPSC function via TRPV1-mediated $\mathrm{Ca}^{2+}$ influx-stimulated glycogen synthase kinase-3 $\beta$ $($ GSK $3 \beta) / \beta$-catenin pathway.

\section{Results}

DPSCs expressed CBS, CSE, and produced $\mathrm{H}_{2} \mathrm{~S}$

Aberrant $\mathrm{H}_{2} \mathrm{~S}$ metabolism has been linked to MSC dysfunction; here we revealed that DPSCs expressed CBS, CSE, and ubiquitous enzyme MPST, the main catalyzed enzymes of $\mathrm{H}_{2} \mathrm{~S}$ synthesis (Fig. 1a, c and Supplementary 
a
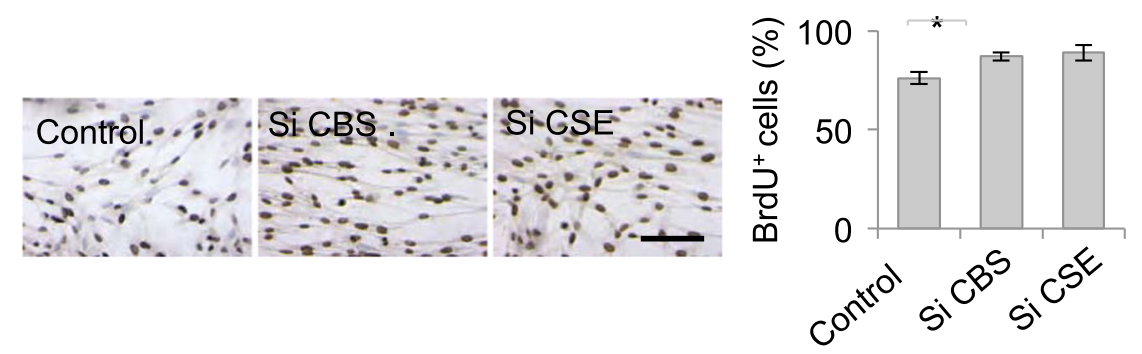

b
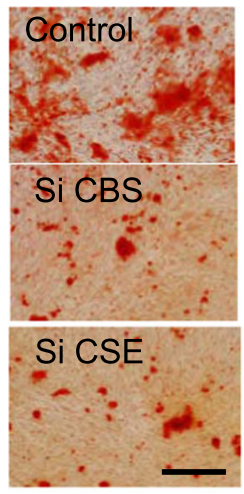

d
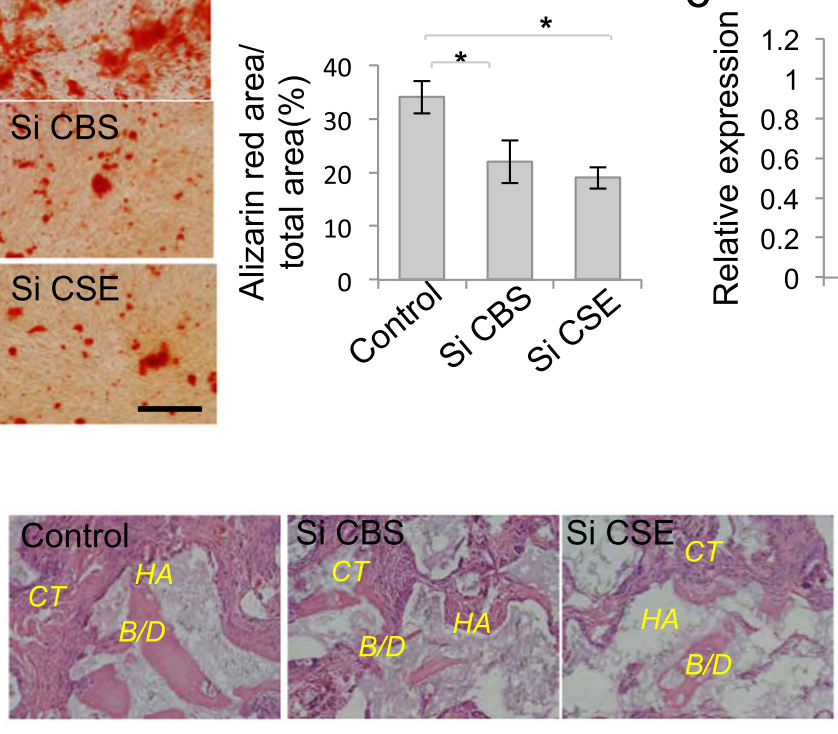

C

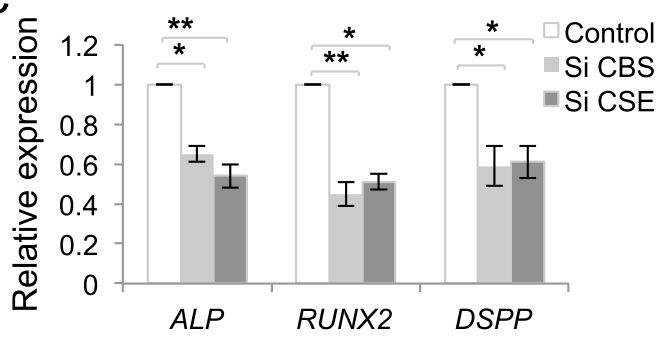

e

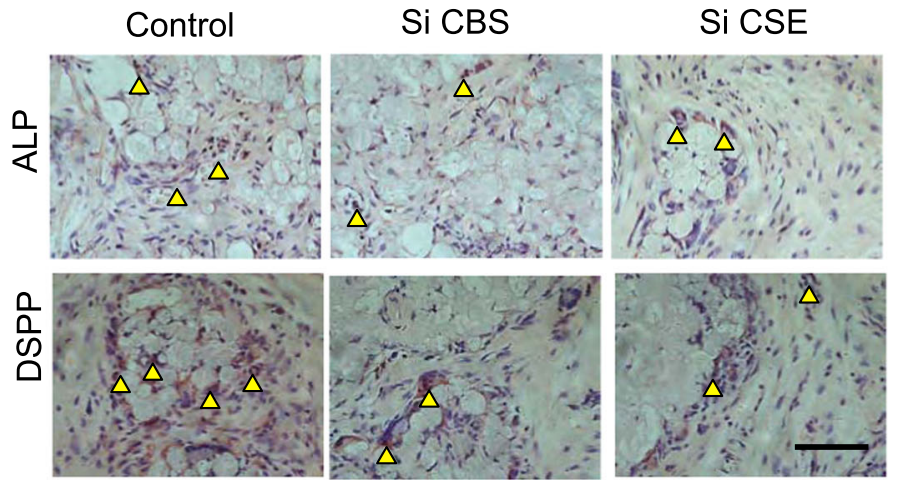

Figure $2 \mathrm{H}_{2} \mathrm{~S}$ was required to maintain homeostasis of DPSCs. a DPSC proliferation was increased after CBS or CSE siRNA treatment, as assessed by BrdU proliferation assay (a). b, c CBS or CSE siRNA treatment decreased DPSC osteogenic/dentiogenic differentiation, as assessed by Alizarin red staining, with decreased expression of RUNX2, ALP, and DSPP analyzed by GPCR. $\mathbf{d}$ When DPSCs were subcutaneously implanted into

immunocompromised mice using HA/TCP as a carrier, bone/dentin-like hard tissue formation of DPSCs was decreased after CBS or CSE siRNA treatment. e ALP-positive and DSPP-positive cells were detected in the tissue formed by DPSC in vivo transplantation. CBS or CSE siRNA treatment decreased ALP-positive and DSPP-positive cells compared to the control ones. ${ }^{*} P<0.05$, ${ }^{*} P<0.01$; scale bar: $100 \mu \mathrm{m}(\mathbf{a}, \mathbf{b}, \mathbf{d}), 50 \mu \mathrm{m}(\mathbf{e})$. HA HA/TCP, $\mathrm{CT}$ connect tissue, B/D bone/dentin. All experimental data were verified in at least three independent experiments

Figure 1). Meanwhile, DPSCs produced $\mathrm{H}_{2} \mathrm{~S}$ in the culture supernatant, which was downregulated by CBS small interfering RNA (siRNA) or CSE siRNA treatment but not
MPST siRNA treatment (Fig. 1d), and $\mathrm{H}_{2} \mathrm{~S}$ concentration was upregulated by $\mathrm{H}_{2} \mathrm{~S}$ donor NaHS treatment (Fig. 1d). 

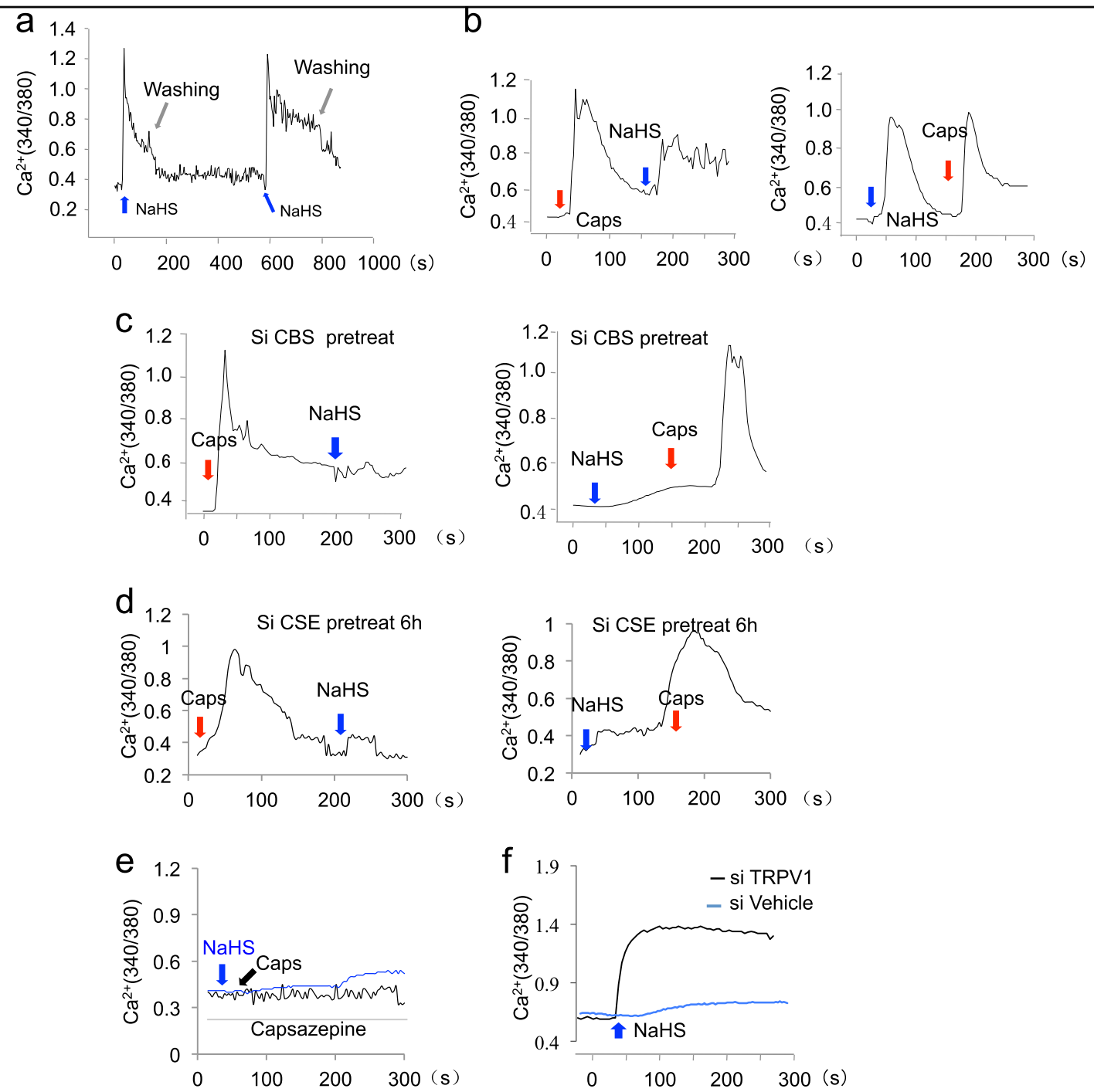

Figure $3 \mathrm{H}_{2} \mathrm{~S}$ activated TRPV1-mediated $\mathrm{Ca}^{2+}$ influx. a NaHS treatment could induce $\mathrm{Ca}^{2+}$ influx in DPSCs, as assessed by $\mathrm{Ca}^{2+}$ levels using the ratio of emission in response to excitation at 340 and $380 \mathrm{~nm}$ on an Olympus Optical IX71 microscope. $\mathbf{b}$ NaHS treatment could induce Ca ${ }^{2+}$ influx in DPSCs as capsaicin treatment. c Capsaicin, but not NaHS, could induce $\mathrm{Ca}^{2+}$ influx in CBS siRNA-pre-treated DPSCs. d Capsaicin, but not NaHS, could induce $\mathrm{Ca}^{2+}$ influx in CSE siRNA-pre-treated DPSCs. e Both capsaicin-induced and NaHS-induced $\mathrm{Ca}^{2+}$ influx was blocked by capsazepine treatment. $\mathbf{f}$ Knockdown of TRPV1 by siRNA could partially block the $\mathrm{Ca}^{2+}$ influx induced by NaHS treatment. Caps capsaicin. All experimental data were verified in at least three independent experiments

\section{$\mathrm{H}_{2} \mathrm{~S}$ maintained DPSC function}

To analyze the role of $\mathrm{H}_{2} \mathrm{~S}$ on DPSC function, we used CBS or CSE siRNA to treat DPSCs and found that DPSC proliferation was increased after CBS or CSE siRNA treatment (Fig. 2a and Supplementary Figure 2a). CBS or CSE siRNA treatment inhibited DPSC osteogenic/dentinogenic differentiation, accompanied by decreased expression of osteogenesis-related genes RUNX2 and $A L P$, and dentin sialophosphoprotein (DSPP) (Fig. 2b, c). CSE, but not CBS, siRNA treatment decreased the adipogenic differentiation of DPSCs, along with decreased expression of adipogenesis-related genes $L P L$ and PPAR (Supplementary Figure 2b, 2c). When DPSCs were subcutaneously implanted into immunocompromised mice using hydroxyapatite/tricalcium phosphate (HA/ $\mathrm{TCP}$ ) as a carrier, bone/dentin-like hard tissue formation were observed. After CBS or CSE siRNA treatment, bone/ dentin-like hard tissue formation of DPSCs was decreased (Fig. 2d). Moreover, ALP-positive and DSPP-positive cells were detected in the tissues formed by DPSC transplantation in vivo, while ALP-positive and DSPP-positive cells were decreased after CBS or CSE siRNA treatment (Fig. 2e). These data implied that DPSCs could differentiate into functional odontoblast-like cells and osteoblast in vitro and in vivo, which was attenuated by $\mathrm{H}_{2} \mathrm{~S}$ deficiency. 


\section{a}
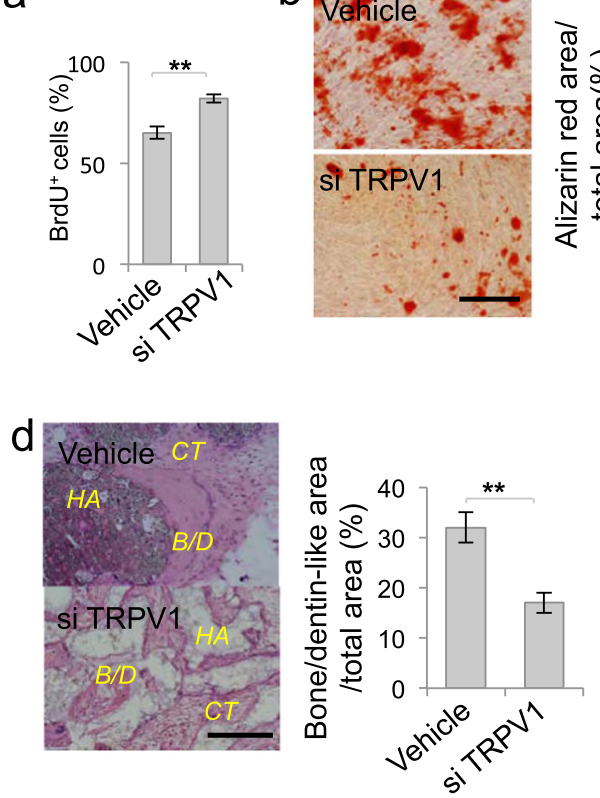

f

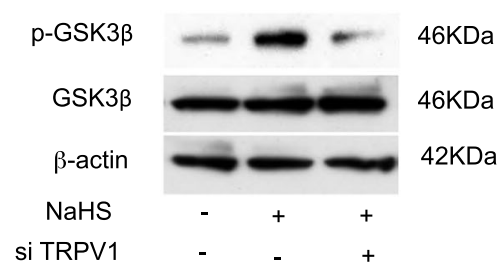

$\mathrm{h}$

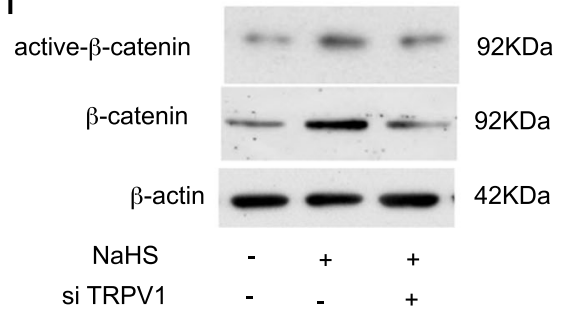

C

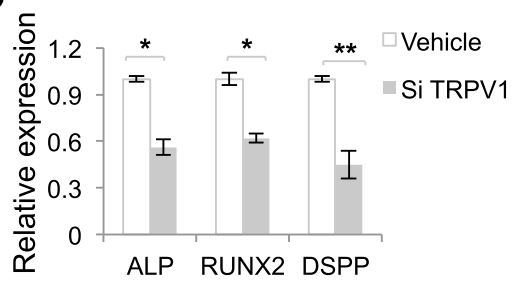

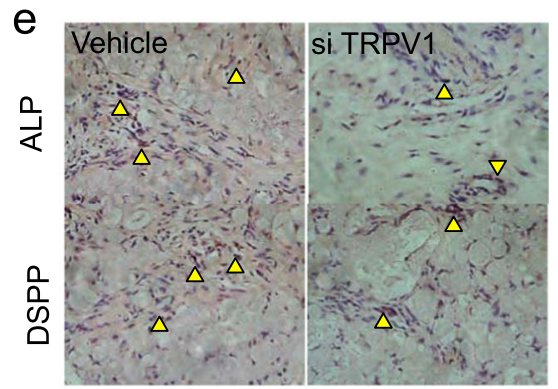

g
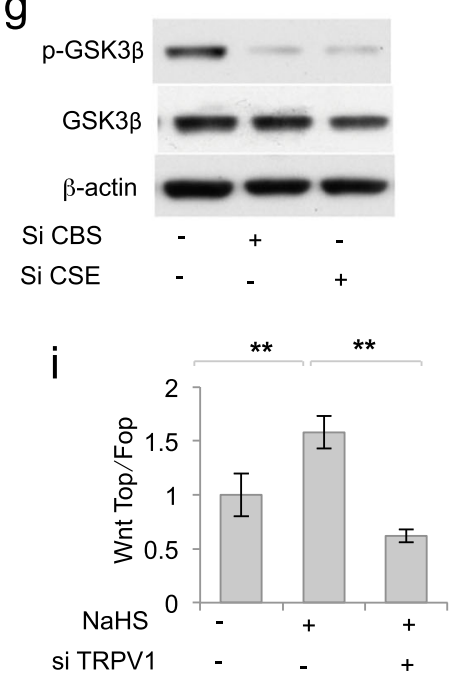

Figure 4 TRPV1-mediated $\mathrm{Ca}^{2+}$ influx was required to maintain DPSC function. a DPSC proliferation was increased after TRPV1 knockdown, as assessed by BrdU proliferation assay. b, c DPSC osteogenic/dentinogenic differentiation was decreased after TRPV1 knockdown, as assessed by Alizarin red staining, with decreased expression of RUNX2, ALP, and DSPP analyzed by qPCR. $\mathbf{d}$ Bone/dentin-like hard tissue formation of DPSCs in vivo decreased after TRPV1 knockdown by siRNA. e ALP-positive and DSPP-positive cells detected in tissues formed by DPSC transplantation were decreased after TRPV1 knockdown. f NaHS treatment upregulated p-GSK3 $\beta$ expression, and knockdown of TRPV1 by siRNA partially blocked NaHSinduced GSK3 $\beta$ phosphorylation. $\mathbf{g}$ CBS or CSE siRNA treatment downregulated p-GSK3 $\beta$ expression. $\mathbf{h} \mathrm{H}_{2} \mathrm{~S}$ donor NaHS treatment activated $\beta$ catenin expression, which was partially blocked after TRPV1 knockdown. i NaHS treatment enhanced TOPflash activity in DPSCs, which was blocked after TRPV1 siRNA treatment, as assessed by luciferase activity. NaHS treatment failed to alter FOPflash activity. HA HA/TCP, CT connect tissue, B/D bone/dentin. ${ }^{*} P<0.05,{ }^{* *} P<0.01$; scale bar: $100 \mu \mathrm{m}(\mathbf{b}, \mathbf{d}), 50 \mu \mathrm{m}(\mathbf{e})$. All experimental data were verified in at least three independent experiments

\section{$\mathrm{H}_{2} \mathrm{~S}$ activated TRPV1-mediated $\mathrm{Ca}^{2+}$ influx}

Emerging evidences showed that $\mathrm{H}_{2} \mathrm{~S}$ plays crucial role in maintaining calcium homeostasis in endothelial cells, cardiomyocytes, and $\mathrm{MSCs}^{18}$. Here we found that $\mathrm{H}_{2} \mathrm{~S}$ donor NaHS treatment induced $\mathrm{Ca}^{2+}$ influx in DPSCs (Fig. 3a). The TRPV subfamily is $\mathrm{Ca}^{2+}$-permeable cation channel, which could be activated by different stimuli.
Our previous study revealed that combined TRPV3, TRPV6, and TRPM4 $\mathrm{Ca}^{2+}$ channels mediated $\mathrm{Ca}^{2+}$ influx-promoted osteogenic differentiation of BMMSCs ${ }^{6}$. First, we used TRPV3, TRPV6, and TRPM4 siRNAs individually or in combination to treat DPSCs and found that inhibition of these $\mathrm{Ca}^{2+}$ channels could not block NaHS-induced $\mathrm{Ca}^{2+}$ influx (Supplementary Figure 3). 
a

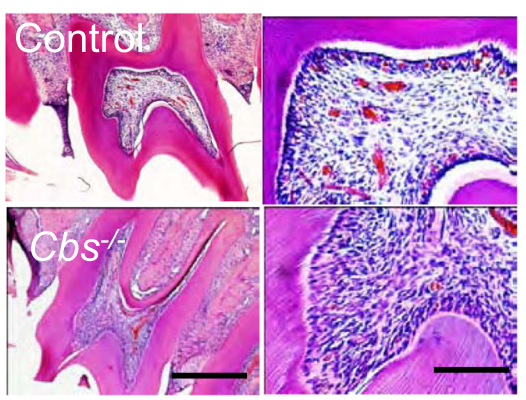

C
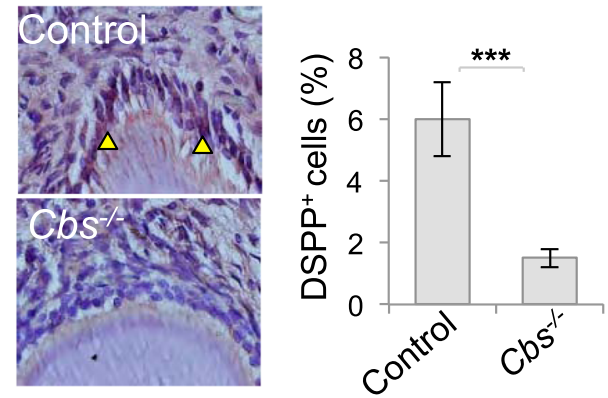

e
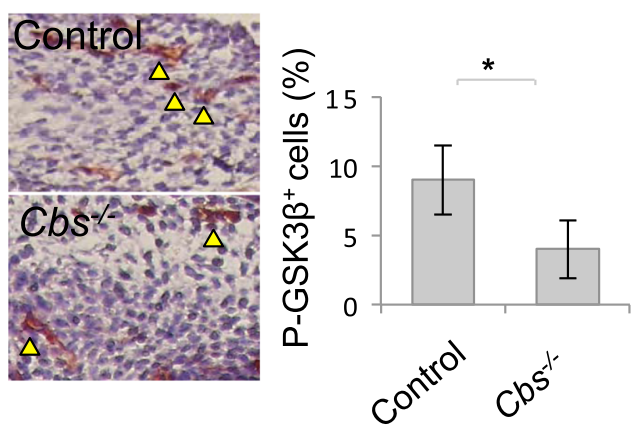
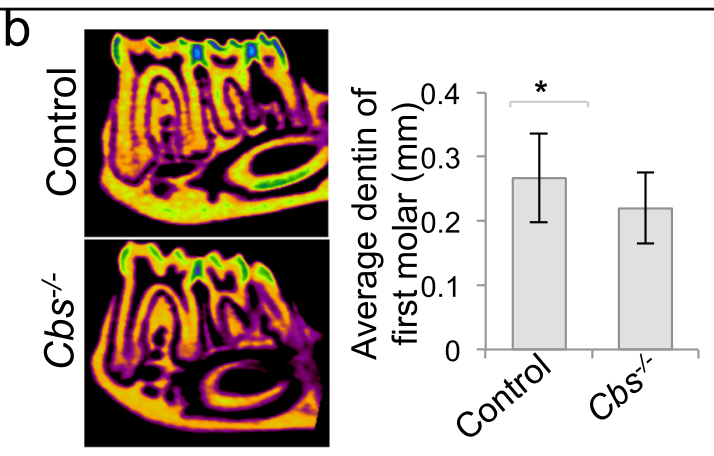

d
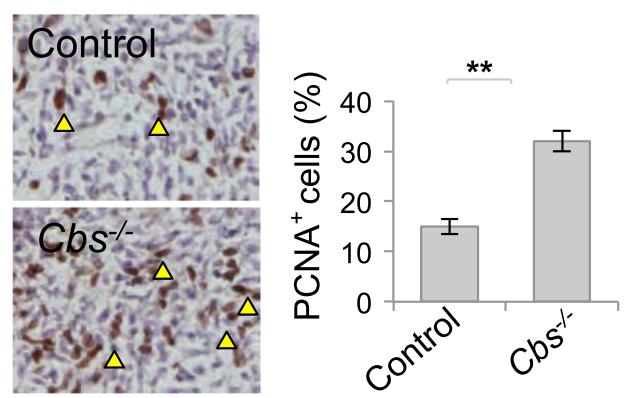

f
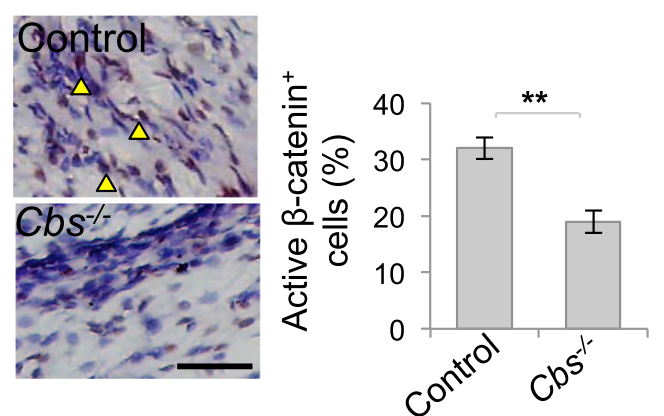

Figure 5 $\beta$-Catenin signaling were decreased in $\mathrm{Cbs}^{-1-}$ dental pulp. a $\mathrm{Cbs}^{-1-}$ mice dental pulp showed more cells than control ones. $\mathbf{b}$ The

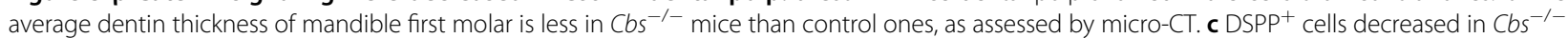
mice dental pulp compared to control ones. $\mathbf{d}$ PCNA ${ }^{+}$cells increased in $\mathrm{Cbs}^{-1-}$ mice dental pulp. e, $\mathbf{f} \mathrm{p}-\mathrm{GSK} 3 \beta^{+}$and active- $\beta$-catenin cells decreased in $\mathrm{Cbs}^{-1-}$ mice dental pulp. ${ }^{*} P<0.05,{ }^{*} P<0.01,{ }^{* *} P<0.001$, scale bar: $200 \mu \mathrm{m}$ left panel, $100 \mu \mathrm{m}$ right panel (a), $1 \mathrm{~mm}$ (b), $20 \mu \mathrm{m}(\mathbf{c}-\mathbf{f})$. All experimental data were verified in at least three independent experiments

Studies found that TRPV1 was expressed in osteoblasts and was important in maintaining osteoblast differentiation ability ${ }^{19}$. Here we revealed that capsaicin, which acts on the TRPV1 receptor in nociceptive neurons to activate calcium influx, induced $\mathrm{Ca}^{2+}$ influx in DPSCs. NaHS treatment induced similar $\mathrm{Ca}^{2+}$ influx as capsaicin in DPSCs (Fig. 3b). When DPSCs were pretreated with CBS or CSE siRNA treatment, attenuated NaHS, but not capsaicin, triggered $\mathrm{Ca}^{2+}$ influx (Fig. 3c, d). When DPSCs were pretreated with capsazepine, a competitive antagonist of TRPV1, the $\mathrm{Ca}^{2+}$ influx induced both by NaHS and capsaicin were blocked, which indicated that TRPV1 channels play a crucial role in mediated $\mathrm{H}_{2} \mathrm{~S}$-induced $\mathrm{Ca}^{2+}$ influx in DPSCs (Fig. 3e). Furthermore, we found that knockdown of TRPV1 by siRNA blocked NaHS-triggered $\mathrm{Ca}^{2+}$ influx in DPSCs (Fig. 3f), verifying that $\mathrm{H}_{2} \mathrm{~S}$ stimulates TRPV1 channel to trigger $\mathrm{Ca}^{2+}$ influx in DPSCs.

\section{TRPV1-mediated $\mathrm{Ca}^{2+}$ influx was required to maintain DPSC function}

To verify the role of TRPV1-mediated $\mathrm{Ca}^{2+}$ influx in DPSCs, we analyzed DPSC function after TRPV1 knockdown and revealed that DPSC proliferation was increased after TRPV1 knockdown (Fig. 4a). DPSC osteogenic/ dentinogenic differentiation was decreased, along with downregulated expression of RUNX2, ALP, and DPSS after TRPV1 knockdown by siRNA (Fig. 4b, c). Moreover the in vivo bone/dentin-like hard tissue formed by DPSC 
transplantation also decreased after TRPV1 knockdown, which was consistent with $\mathrm{H}_{2} \mathrm{~S}$ deficiency. (Fig. 4d). Consistently, less ALP-positive and DSPP-positive cells were detected in the tissues formed by DPSC transplantation after TRPV1 siRNA treatment (Fig. 4e). These studies indicate that TRPV1-mediated $\mathrm{Ca}^{2+}$ influx play crucial roles in maintaining DPSC function.

\section{$\mathrm{H}_{2} \mathrm{~S}$ activated $\beta$-catenin signaling}

Next, we analyzed the underlying mechanisms of how $\mathrm{Ca}^{2+}$ influx regulated DPSC function. We used $\mathrm{H}_{2} \mathrm{~S}$ donor $\mathrm{NaHS}$ to treat DPSCs and found that NaHS treatment elevated phosphorylation of GSK3 3 , while knockdown of TRPV1 by siRNA blocked NaHS-induced phosphorylated-GSK3 $\beta$ (p-GSK3 $\beta$ ) elevation (Fig. 4f). Consistently, we revealed that CBS or CSE siRNA treatment downregulated p-GSK3 $\beta$ expression (Fig. 4g). $\beta$-Catenin signaling plays crucial roles in determining stem cell lineage differentiation ${ }^{1}$. We found that $\mathrm{H}_{2} \mathrm{~S}$ donor NaHS treatment increased $\beta$-catenin and active- $\beta$-catenin expression, which was blocked by TRPV1 knockdown (Fig. 4h). Next, we investigated whether $\mathrm{H}_{2} \mathrm{~S}$ affected $\beta$-catenin transcriptional activity by using luciferase assay analyzed by the ratio of TOPflash and FOPflash. The results showed that $\mathrm{H}_{2} \mathrm{~S}$ donor NaHS treatment increased pathway activity. TRPV1 siRNA treatment attenuated NaHSinduced pathway activity elevation (Fig. 4i). These data implied that $\mathrm{H}_{2} \mathrm{~S}$ gasotransmitter pathway activated $\beta$-catenin signaling in DPSCs.

\section{$\mathrm{H}_{2} \mathrm{~S}$-mediated $\beta$-catenin signaling contributed to dentin formation}

In order to verify the role of $\beta$-catenin cascade in maintaining dental pulp homeostasis, we employed $\mathrm{H}_{2} \mathrm{~S}$ deficient $\left(\mathrm{Cbs}^{-1-}\right)$ mice and found that $\mathrm{Cbs}^{-1-}$ mice dental pulp showed disturbed pattern with increased cell infiltration than control ones (Fig. 5a). The average thickness of dentin was decreased in $\mathrm{Cbs}^{-1-}$ mice with decreased DSPP-positive cells in the dental pulp compared to control ones (Fig. 5b, c). Furthermore, proliferative $\mathrm{PCNA}^{+}$cells increased in $\mathrm{Cbs}^{-1-}$ mice dental pulp (Fig. $5 \mathrm{~d}$ ), while p-GSK3 $\beta^{+}$and active- $\beta$-catenin ${ }^{+}$ cells decreased in $\mathrm{Cbs}^{-/-}$mice dental pulp (Fig. 5e, f), which to some extent verifies that $\mathrm{H}_{2} \mathrm{~S}$-mediated $\beta$-catenin signaling is important in maintaining dentin formation and DPSC function in vivo.

\section{Discussion}

$\mathrm{H}_{2} \mathrm{~S}$ regulates several physiological and pathological processes via diverse mechanisms. In this study, we showed that $\mathrm{H}_{2} \mathrm{~S}$ is essential to maintain DPSC osteogenic and dentinogenic differentiation. We used siRNA to knockdown CBS and CSE, the main enzymes that catalyzed $\mathrm{H}_{2} \mathrm{~S}$ production in DPSCs, and found that DPSC proliferation was elevated. There were more $\mathrm{PCNA}^{+}$cells infiltrated in $\mathrm{Cbs}^{-1-}$ mice dental pulp, indicating that $\mathrm{H}_{2} \mathrm{~S}$ is required to restrict aberrant proliferation of stem cells, which is consistent with previous reports ${ }^{15}$. Furthermore, we found that the dentin thickness in $\mathrm{Cbs}^{-1-}$ mice decreased compared to the control ones, which was consistent with the decreased osteogenic and dentinogenic differentiation of $\mathrm{H}_{2} \mathrm{~S}$ deficiency DPSCs in vitro and in vivo. These results expand the physiological roles of $\mathrm{H}_{2} \mathrm{~S}$ in MSCs from bone to dental pulp and dentin homeostasis.

Calcium channels were one of main cellular events that may contribute $\mathrm{H}_{2} \mathrm{~S}$-mediated molecular responses ${ }^{20,21}$. The L-type and T-type $\mathrm{Ca}^{2+}$ channels and TRP channels are reported to be the alternative targets of $\mathrm{H}_{2} \mathrm{~S}$. TRP channels were involved in diverse cellular functions such as gene expression, proliferation, differentiation, migration, and apoptosis. It is reported that $\mathrm{H}_{2} \mathrm{~S}$ triggers TRPV1 to mediate chloride secretion in acute pancreatitis and colon $^{22,23}$. In this study, we found that $\mathrm{H}_{2} \mathrm{~S}$ donors mimicked the effect of capsaicin in the neurons, leading to the $\mathrm{Ca}^{2+}$ flux entry in DPSCs. $\mathrm{Ca}^{2+}$ influx entry then triggered GSK3 $\beta / \beta$-catenin cascade to regulate DPSC proliferation and differentiation. Furthermore, the study revealed that TRPV1 was essential to maintain DPSC proliferation and differentiation. When TRPV1 was knocked down by siRNA in DPSCs, the proliferation of DPSCs was elevated and osteogenic/dentinogenic differentiation of DPSCs was inhibited, which firstly implied the role of TRPV1 in maintaining MSC capacity. Our previous study reported that $\mathrm{H}_{2} \mathrm{~S}$-triggered $\mathrm{Ca}^{2+}$ influx is required to maintain bone and MSC homeostasis. The study revealed that combined TRPV3, TRPV6, and TRPM4 $\mathrm{Ca}^{2+}$ channels mediated $\mathrm{Ca}^{2+}$ influx to promote osteogenic differentiation of BMMSCs ${ }^{6}$. In this study, we found that the proliferation and differentiation capacity of DPSCs could not be attenuated by TRPV3, TRPV6, and TRPM4 $\mathrm{Ca}^{2+}$ channels blockage. These differences may attribute that DPSCs were derived from the neural crest and mesoderm during development, which were more accessible to differentiate into dentin-like tissue rather than the bone compared to BMMSCs. Functionally, DPSCs also easily differentiated into neuronal and glial cells and acted as neuronal cells ${ }^{24,25}$. These studies shed light on the different molecular target induced by $\mathrm{H}_{2} \mathrm{~S}$ to illustrate the unique properties of MSCs derived from different tissues

Variety of signal pathways may contribute to that $\mathrm{H}_{2} \mathrm{~S}$ fine-tune its effects on different tissues and cells. $\mathrm{H}_{2} \mathrm{~S}$ may trigger the nuclear translocation of nuclear factor- $\mathrm{kB}$ (NF$\kappa B)$ and affect the activity of numerous kinases including p38 mitogen-activated protein kinase, extracellular signalregulated kinase, and Akt signaling. $\mathrm{H}_{2} \mathrm{~S}$ is able to promote angiogenesis and vascular remodeling via the PI3K/ 
Akt/survivin axis in endothelial cells by augmenting phosphorylation of ERK and p38 $8^{20,21} \cdot \mathrm{H}_{2} \mathrm{~S}$ deceases proinflammatory genes involved in cardiac ischemic/reperfusion injury via inhibiting the nuclear translocation of NF- $\mathrm{KB}^{26}$. In BMMSCs, $\mathrm{H}_{2} \mathrm{~S}$-induced $\mathrm{Ca}^{2+}$ influx promoted $\beta$-catenin activity via the PKC/ERK pathway to maintain bone homeostasis ${ }^{6}$. However, we found that $\mathrm{H}_{2} \mathrm{~S}$ treatment failed to alter ERK signaling in DPSCs (data were not shown). We showed that TRPV1-mediated $\mathrm{Ca}^{2+}$ influx entry facilitates the phosphorylation of GSK3 $\beta$ to disrupt the "destruction complex." $\beta$-Catenin accumulates in the cytoplasm and then translocates into the nucleus, which promoted DPSC osteogenic differentiation. $\mathrm{H}_{2} \mathrm{~S}$ deficiency decreased TRPV1-mediated $\mathrm{Ca}^{2+}$ influx entry, leading to decreased phosphorylation of GSK3 $\beta$. These data indicated that the response of different stem cells to $\mathrm{H}_{2} \mathrm{~S}$ may be regulated by different signaling pathways.

Cytoplasmic $\beta$-catenin was degraded, resulting in DPSC osteogenic differentiation deficiency. In vivo, $\mathrm{Cbs}^{-1-}$ mice dental pulp showed elevated cell infiltration and proliferation and decreased GSK3 $\beta / \beta$-catenin signaling. Moreover, the dentin formation of $\mathrm{Cbs}^{-1-}$ mice was less than control ones. These data suggest that $\mathrm{H}_{2} \mathrm{~S}$-mediated GSK3 $\beta / \beta$-catenin cascade is important to maintain DPSC function and dental pulp homeostasis. These results shed light on the different biology and mechanism of $\mathrm{H}_{2} \mathrm{~S}$ targeting on different MSCs and tissue homeostasis.

\section{Conclusion}

Our study reveals that the levels of $\mathrm{H}_{2} \mathrm{~S}$ are essential to maintain $\mathrm{Ca}^{2+}$ homeostasis via TRPV1 $\mathrm{Ca}^{2+}$ channel in DPSCs. $\mathrm{H}_{2} \mathrm{~S}$ deficiency results in $\mathrm{Ca}^{2+}$ influx/GSK3 $\beta / \beta-$ catenin cascade response in DPSCs, leading to differentiation deficiency of DPSCs and dentin formation disorders (Supplementary Figure 4).

\section{Materials and methods \\ Mice}

C57BL/6 (JAX \#000664), B6.129P2-Cbstm1Unc/J (JAX $\#$ 002461) $\mathrm{Cbs}^{+/-}$mice were purchased from Jackson lab. Female immunocompromised mice (beige nude/nude XIDIII) were purchased from Harlan Laboratories. All animal experiments were performed under institutionally approved protocols for the use of animal research at the University of Pennsylvania (IACUC\# 805478) and Peking University (\#LA2012-65).

\section{Antibodies and chemicals Antibodies}

Anti-active- $\beta$-catenin and $\beta$-catenin antibodies were purchased from Millipore (Temecula, CA, USA). AntiCD105-PE, anti-CD146-PE, anti-CD90-PE, anti-CD34$\mathrm{PE}$, and anti-CD45-PE antibodies were purchased from BD Bioscience (San Jose, CA, USA). Unconjugated
anti-GSK3 $\beta$ and anti-phospho-GSK3 $\beta$ antibodies were purchased from Cell Signaling Inc. (San Francisco, CA, USA). Anti- $\beta$-actin antibody was purchased from SigmaAldrich Corporation (St. Louis, MO, USA). Unconjugated anti-CBS, CSE, DSPP (DSP) and TRPV1 were purchased from Abcam Inc. (Cambridge, MA, USA).

\section{Chemicals}

siRNA for CBS (hydroxylamine), CSE (DL-propargylglycine), TRPV1, TRPV3, TRPV6, and TRPM4 were purchased from Santa Cruz. $\mathrm{H}_{2} \mathrm{~S}$ donor NaHS was purchased from Sigma-Aldrich Corporation (St. Louis, MO, USA). Capsaicin and capsazepine were purchased from EMD Millipore (Billerica, MA, USA). The concentrations of capsaicin and capsazepine used for the treatment were $1 \mu \mathrm{M}$.

\section{Isolation and culture of human bone DPSCs}

Dental pulp from human extracted wisdom teeth were gently separated, minced, and digested with $2 \mathrm{mg} / \mathrm{ml}$ collagenase type I (Worthington Biochemical, Freehold, NJ, USA) and $4 \mathrm{mg} / \mathrm{ml}$ dispase II (Roche Diagnostics, Indianapolis, IN, USA) in phosphate-buffered saline for 1 $\mathrm{h}$ at $37^{\circ} \mathrm{C}$. Then, the cells were passed through a $70-\mu \mathrm{m}$ strainer (BD Biosciences, Franklin Lakes, NJ, USA) to get single cells. The single-cell suspensions were cultured with $\alpha$-minimum essential medium ( $\alpha$-MEM) supplemented with $15 \%$ fetal bovine serum (FBS), $100 \mathrm{mM} \mathrm{L-}$ ascorbic acid-2-phosphate, $2 \mathrm{mM}$ L-glutamine, $100 \mathrm{U} / \mathrm{ml}$ penicillin, and $100 \mu \mathrm{g} / \mathrm{ml}$ streptomycin and passaged, as previously reported ${ }^{27}$.

\section{Human bone marrow MSCs BMMSC culture}

Human bone marrow aspirates from healthy adult donors (20-35 years of age) were purchased from AllCells (Emeryville, CA, USA). Human bone marrow progenitor cells were enriched using fresh human bone marrow by RosetteSep Human Bone Marrow Progenitor Cell PreEnrichment Cocktail (STEMCELL Technologies, Vancouver, BC, Canada) following the manufacturer's instructions. The enriched single-cell suspensions were cultured with $\alpha$-MEM supplemented with 15\% FBS, 100 $\mathrm{mM}$ L-ascorbic acid-2-phosphate, $2 \mathrm{mM}$ L-glutamine, 100 $\mathrm{U} / \mathrm{ml}$ penicillin, and $100 \mu \mathrm{g} / \mathrm{ml}$ streptomycin and passaged, as previously reported ${ }^{27}$.

\section{Cell proliferation assay}

DPSCs were passaged to a 4-well chamber slide (Nunc, $1 \times 10^{4}$ per well) and incubated for $12 \mathrm{~h}$ at $37^{\circ} \mathrm{C}$ in a $5 \%$ $\mathrm{CO}_{2}$ condition. Then, the cells were assayed for bromodeoxyuridine (BrdU) incorporation, as per the manufacturer's instruction. $\mathrm{BrdU}^{+}$and total cell numbers were counted in five images per subject. The $\mathrm{BrdU}^{+}$cells were 
indicated as a percentage of $\mathrm{BrdU}^{+}$cells and the total cell number.

\section{DPSC-mediated hard tissue formation in vivo}

Approximately $4.0 \times 10^{6}$ DPSCs were mixed with HA/ TCP ceramic particles (40 mg, Zimmer Inc., Warsaw, IN, USA) as a carrier and subcutaneously implanted into the dorsal surface of 8- to 10-week-old immunocompromised mice $(n=4)$. At 8 weeks post-implantation, the implants were harvested, fixed in $4 \%$ paraformaldehyde, and then decalcified with 5\% EDTA, followed by paraffin embedding. The $5 \mu \mathrm{m}$ paraffin sections were stained with hematoxylin and eosin and analyzed by NIH ImageJ. The newly formed mineralized tissue area in each field was calculated and shown as a percentage of the total tissue area.

\section{Osteogenic/dentinogenic differentiation assay}

Osteogenic/dentinogenic differentiation is performed as described in the Supplementary materials.

\section{Adipogenic differentiation assay}

Adipogenic differentiation is performed as described in the Supplementary materials.

\section{Immunofluorescent staining}

DPSCs were seeded on a 4-well chamber slide and incubated for $12 \mathrm{~h}$ at $37^{\circ} \mathrm{C}$ in a $5 \% \mathrm{CO}_{2}$ condition. The detailed method of immunofluorescent staining is described in the Supplementary materials.

\section{Immunohistochemical staining}

Immunohistochemical staining is performed as described in the Supplementary materials.

\section{Western blot}

Western blot is performed as described in the Supplementary materials.

\section{Quantitative PCR}

For quantitative PCR (qPCR) analysis, total RNA was extracted with RNeasy Mini kit (Qiagen, Valencia, CA, USA), and complementary DNA was prepared using a SuperScript ${ }^{\oplus}$ III Reverse Transcriptase (RT) kit (Invitrogen). qPCR was carried out using SYBR ${ }^{\oplus}$ Green Supermix (Bio-Rad) on a Bio-Rad CFX96 Real Time System, as indicated by the manufacturer's protocol.

\section{Measurement of $\mathrm{Ca}^{2+}$ image}

DPSCs $\left(1 \times 10^{5}\right)$ were seeded onto $60 \mathrm{~mm}$ culture dishes and cultured for $24 \mathrm{~h}$ at $37^{\circ} \mathrm{C}$ in $5 \% \mathrm{CO}_{2}$. Then, the cells were loaded with fura-2 AM (Invitrogen) and incubated for $1 \mathrm{~h}$ at $37^{\circ} \mathrm{C}$ in $5 \% \mathrm{CO}_{2}$ in the dark. $\mathrm{Ca}^{2+}$ levels were measured from the ratio of emission in response to excitation at 340 and $380 \mathrm{~nm}$ on an Olympus Optical IX71 microscope.

\section{Measurement of $\mathrm{H}_{2} \mathrm{~S}$}

Cell culture supernatants were mixed with $0.25 \mathrm{ml} \mathrm{Zn}$ acetate (1\%) and $0.45 \mathrm{ml}$ water for $10 \mathrm{~min}$ at room temperature. TCA $(10 \% ; 0.25 \mu \mathrm{l})$ was then added and centrifuged $\left(14,000 \times g\right.$ for $10 \mathrm{~min}$ at $\left.4{ }^{\circ} \mathrm{C}\right)$. The supernatant was then collected and mixed with $N, N$-dimethyl-p-phenylenediamine sulfate $(20 \mu \mathrm{M})$ in $1.2 \mathrm{M} \mathrm{HCl}$ and $\mathrm{FeCl}_{3}$ $(30 \mu \mathrm{M})$ in $1.2 \mathrm{~mol} / \mathrm{l} \mathrm{HCl}$. After $20 \mathrm{~min}$, absorbance was measured at $650 \mathrm{~nm}$.

\section{In vitro transcription assays}

$\beta$-Catenin-mediated transcriptional activity was measured by the luciferase activity by using TOPflash and FOPflash described previously ${ }^{6}$. DPSCs $\left(1 \times 10^{5}\right)$ were seeded onto a 24-well culture plate and cultured for $24 \mathrm{~h}$. TOPflash or FOPflash (10 ng/well) and renilla luciferase (4 ng/well) were transfected into DPSCs using a Lipofectamine $^{\mathrm{rm}}$ RNAiMAX kit (Invitrogen). After $15 \mathrm{~h}$, the plates were assayed for firefly luciferase and renilla luciferase activities using the Dual-Luciferase ${ }^{\circledast}$ Reporter Assay System (Promega).

\section{Micro computed tomography}

The mandible of mice was scanned with a microcomputed tomography (micro-CT) system (Inveon MMCT, Berlin, Germany) at $80 \mathrm{kV}, 500 \mu \mathrm{A}$, and an image voxel size of $18 \mu \mathrm{m}$. The hemi-mandibles were excised ( $n$ $=6$ per group). The hemi-mandible samples were directed parallel to the occlusal plane and scanned for 2.70 $\mathrm{mm}$. The thickness of the first molar was measured with the DataViewer software (ver. 1.4.3; SkyScan).

\section{Statistical analysis}

$P$ values were analyzed from two-tailed Student's $t$ test for the difference between two groups or one-way analysis of variance to compare the difference from more than two groups using the SPSS 18.0 software. $P$ values $<0.05$ were considered significant.

\section{Acknowledgements}

This work was supported by Supported by Beijing Natural Science Foundation (7182182), the Young Elite Scientist Sponsorship Program by CAST

(2017QNRC001), International Science \& Technology Cooperation Program of China No. 2015 DFB30040 (to Y.Z.), the National Science Foundations of China, No. 81470717 (to Y.Z.), 81600865 (to R.Y.), and 81570953 (to Y.S. Z.).

\section{Author details}

'Department of Orthodontics, Peking University School and Hospital of Stomatology, 100081 Beijing, China. ${ }^{2}$ National Engineering Laboratory for Digital and Material Technology of Stomatology, Beijing Key Laboratory of Digital Stomatology, 100081 Beijing, China. ${ }^{3}$ Department of Anatomy and Cell Biology, School of Dental Medicine, University of Pennsylvania, Philadelphia, PA 19104, USA. ${ }^{4}$ Laboratory of Tissue Regeneration and Immunology and

Department of Periodontics, Beijing Key Laboratory of Tooth Regeneration and Function Reconstruction, Capital Medical University School of Stomatology, 
100050 Beijing, China. ${ }^{5}$ Department of Prosthodontics, Peking University School and Hospital of Stomatology, 100081 Beijing, China

\section{Authors' contributions}

R.Y.: conception and design, collection and assembly of data, data analysis and interpretation, final approval of manuscript; Y.L., T.Y.: collection data and interpretation, final approval of manuscript. Y.H.Z., Y.S. Z., S.S.: critically edited the manuscript, financial support, final approval of manuscript.

\section{Compliance with ethical standards}

\section{Conflict of interest}

The authors declare that they have no conflict of interest.

\section{Publisher's note}

Springer Nature remains neutral with regard to jurisdictional claims in published maps and institutional affiliations.

\section{Supplementary information}

The online version of this article (https://doi.org/10.1038/s41420-018-0071-4) contains supplementary material, which is available to authorized users.

Received: 26 November 2017 Revised: 17 February 2018 Accepted: 20 February 2018

Published online: 27 June 2018

\section{References}

1. Li, J. \& Pei, M. Cell senescence: a challenge in cartilage engineering and regeneration. Tissue Eng. Part B 18, 270-287 (2012).

2. Yang, R. et al. Hydrogen sulfide promotes Tet1- and Tet2-mediated Foxp3 demethylation to drive regulatory $T$ cell differentiation and maintain immune homeostasis. Immunity 43, 251-263 (2015).

3. Oh, S. A. \& Li, M. O. TETs link hydrogen sulfide to immune tolerance. Immunity 43, 211-213 (2015).

4. Wang, Z. et al. L-Cysteine promotes the proliferation and differentiation of neural stem cells via the CBS/H(2)S pathway. Neuroscience 237, 106-117 (2013).

5. Zhao, Y., Wei, H., Kong, G., Shim, W. \& Zhang, G. Hydrogen sulfide augments the proliferation and survival of human induced pluripotent stem cell-derived mesenchymal stromal cells through inhibition of BKCa. Cytotherapy 15, 1395-1405 (2013).

6. Liu, Y. et al. Hydrogen sulfide maintains mesenchymal stem cell function and bone homeostasis via regulation of Ca channel sulfhydration. Cell Stem Cell. 15, 66-78 (2014).

7. Grassi, F. et al. Hydrogen sulfide is a novel regulator of bone formation implicated in the bone loss induced by estrogen deficiency. J. Bone Miner. Res. 5, 949-963 (2015).
8. Aas, J. A., Paster, B. J., Stokes, L. N., Olsen, I. \& Dewhirst, F. E. Defining the normal bacterial flora of the oral cavity. J. Clin. Microbiol. 43, 5721-5732 (2005).

9. Zhang, J. H., Dong, Z. \& Chu, L. Hydrogen sulfide induces apoptosis in human periodontium cells. J. Periodontal Res. 45, 71-78 (2010).

10. Miura, M. et al. SHED: stem cells from human exfoliated deciduous teeth. Proc Natl. Acad. Sci. USA 100, 5807-5812 (2003).

11. Ishkitiev, $\mathrm{N}$. et al. Hydrogen sulfide increases hepatic differentiation in tooth-pulp stem cells. J. Breath Res. 6, 017103 (2012).

12. Okada, M. et al. Hydrogen sulphide increases hepatic differentiation of human tooth-pulp stem cells compared with human bone marrow stem cells. Int. Endod. J. 47, 1142-1150 (2014).

13. Kobayashi, C. et al. Hydrogen sulfide causes apoptosis in human pulp stem cells. J. Endod. 37, 479-484 (2011).

14. Liu, F. et al. Force-induced $\mathrm{H}_{2} \mathrm{~S}$ by PDLSCs modifies osteoclastic activity during tooth movement. J. Dent. Res. 96, 694-702 (2017).

15. Su, Y. et al. Physiologic levels of endogenous hydrogen sulfide maintain the proliferation and differentiation capacity of periodontal ligament stem cells. J. Periodontol. 86, 1276-1286 (2015).

16. $\mathrm{Pu}, \mathrm{H} . \&$ Hua, $\mathrm{Y}$. Hydrogen sulfide regulates bone remodeling and promotes orthodontic tooth movement. Mol. Med. Rep. 6, 9415-9422 (2017).

17. Aykan, A. et al. The effects of hydrogen sulfide on adipocyte viability in human adipocyte and adipocyte-derived mesenchymal stem cell cultures under ischemic conditions. Ann. Plast. Surg. 75, 657-665 (2015)

18. Munaron, L., Avanzato, D., Moccia, F. \& Mancardi, D. Hydrogen sulfide as a regulator of calcium channels. Cell Calcium 53, 77-84 (2013).

19. He, L. H. et al. TRPV1 deletion impaired fracture healing and inhibited osteoclast and osteoblast differentiation. Sci. Rep. 7, 42385 (2017).

20. Wang, R. Physiological implications of hydrogen sulfide: a whiff exploration that blossomed. Physiol. Rev. 92, 791-896 (2012).

21. Li, L., Rose, P. \& Moore, P. K. Hydrogen sulfide and cell signaling. Annu. Rev. Pharmacol. Toxicol. 51, 169-187 (2011).

22. $\mathrm{Xu}, \mathrm{G}$. Y. et al. The endogenous hydrogen sulfide producing enzyme cystathionine-beta synthase contributes to visceral hypersensitivity in a rat model of irritable bowel syndrome. Mol. Pain 5, 44 (2009).

23. Nishimura, S. et al. Hydrogen sulfide as a novel mediator for pancreatic pain in rodents. Gut 58, 762-770 (2009).

24. Yang, R., Yu, T. \& Zhou, Y. Interplay between craniofacial stem cells and immune stimulus. Stem Cell Res. Ther. 8, 147 (2017).

25. Gronthos, S., Mankani, M., Brahim, J., Robey, P. G. \& Shi, S. Postnatal human dental pulp stem cells (DPSCs) in vitro and in vivo. Proc. Natl. Acad. Sci. USA 97 13625-13630 (2000).

26. Miller, T. W. et al. Hydrogen sulfide is an endogenous potentiator of $\mathrm{T}$ cell activation. J. Biol. Chem. 287, 4211-4221 (2012).

27. Shi, S. et al. Bone formation by human postnatal bone marrow stromal stem cells is enhanced by telomerase expression. Nat. Biotechnol. 20, 587-591 (2002). 